\title{
Guía de buenas prácticas de recolección de indicios en el escenario del delito, según las normas de calidad de laboratorios forenses
}

\author{
Fiorella Rojas-Ballestero* \\ iD https://orcid.org/0000-0003-3429-664X
}

Recibido: 18 de febrero, 2020 - Aceptado: 19 de marzo, 2020

\section{RESUMEN}

El presente artículo expone la metodología seguida en el Trabajo Final de Graduación (TFG) del área de la criminalística, específicamente, el análisis del problema de carecer de un documento guía con sentido de valor probatorio de los indicios que se deben recolectar en un escenario del delito. En este, se genera un desarrollo sistemático mediante el uso del marco lógico de la problemática, hasta llegar a las causas y efectos del problema para llegar a una posible solución con la creación de la Guía de buenas prácticas en la recolección de indicios en el escenario del delito, según las normas de calidad de los laboratorios forenses, específicamente los indicios relacionados con los fluidos biológicos.

Palabras clave: Criminalística, indicios, fluidos biológicos, ADN.

\section{Formato de citación según APA}

Rojas-Ballestero, F. (2020). Guía de buenas prácticas de recolección de indicios en el escenario del delito, según las normas de calidad de laboratorios forenses. Revista Espiga, 19 (39), 99-107.

Formato de citación según Chicago-Deusto

Rojas-Ballestero, Fiorella (2020). «Guía de buenas prácticas de recolección de indicios en el escenario del delito, según las normas de calidad de laboratorios forenses». Revista Espiga 19, n. 39 (enero-junio, 2020): 99-107.

* Licenciada en Criminalística y bachiller en Ciencias Criminológicas, de la Universidad Estatal a Distancia (UNED). Diplomada en Laboratorista Clínico, de la Universidad de Costa Rica (UCR). Egresada del Centro de Estudios del Hemisferio William J. Perry, de la Universidad de Defensa, Washington, D.C., del programa HR/ROL, Derechos Humanos/Estado de Derecho. Laboratorista Forense en la sección de Bioquímica del Departamento de Ciencias Forenses (DCF) del Organismo de Investigación Judicial (OIJ) desde el 2010. Perito Judicial en las secciones de Pericias Físicas y Análisis de Escritura y Documentos Dudosos del mismo departamento. Facilitadora en el Programa Básico de Investigación Criminal, donde brinda, dentro de la materia de Bioquímica, el tema relacionado con la recolección de indicios provenientes de fluidos biológicos y la bioseguridad al manejarlos. Áreas de interés e intereses de investigación: criminalística, delitos sexuales, seguridad social y ciudadana, población vulnerable, estudios de la mujer, ciencias forenses, auditoría forense, derechos humanos, sistema penitenciario. Correo: fiorella.rojas@uned.ac.cr 


\section{Introducción}

El presente trabajo responde a la pregunta ¿Cuál es el contenido de un documento guía de recolección de indicios relacionados con fluidos biológicos, en el que las personas investigadoras utilicen buenas prácticas científico-forenses, generen pensamiento crítico y comprendan que la elección de los indicios está relacionada con el valor que este provea para la posible resolución de un caso?

Esta duda nace luego de revisar el Manual de Recolección de Indicios ya existente en el Departamento de Ciencias Forenses (DCF) del Organismo de Investigación Judicial (OIJ), desde el 2015; este trata sobre cómo manipular lo que se levantó en el escenario, pero no indica la razón o la importancia del porqué levantarlo o no.

De esto surge la idea de crear este proyecto cuyo objetivo principal es diseñar una Guía de buenas prácticas de recolección de indicios con fluidos biológicos en el escenario del delito según las Normas de Calidad Forense para establecer los procedimientos y diagramas necesarios; y con base en eso, determinar qué indicios tienen mayor valor probatorio, al relacionar el trabajo de un investigador, con la capacidad operativa del Laboratorio Forense en Costa Rica; para de este modo obtener mejor tiempo de respuesta de un informe o dictamen pericial.

Así mismo, esta guía sería de conocimiento tanto del personal de investigación, como del personal del Ministerio Público y la Judicatura, ya que tanto fiscales como jueces también deben conocer la importancia, no solo en el nivel jurídico de la prueba, sino su relevancia en el nivel forense, ya que por su formación académica, sus conocimientos forenses son básicos.

Como parte de la experiencia al ser persona facilitadora en el Programa Básico de Investigación Criminal desde el 2015, se hace de manifiesto la necesidad de esta guía; por esto, durante el desarrollo de esta capacitación en 2018, se propone su uso como proyecto y, las personas participantes del Programa Básico, lo ven como un aspecto muy positivo. No obstante, en ese momento, al ser únicamente la propuesta del proyecto, se parte de las observaciones dadas por esas generaciones del Programa.

Para el 2019, durante la realización de la capacitación a las generaciones 76-77-78 y 79 del Programa Básico, ya se les enseña con base en esa guía (aún en borrador); en ella, sus participantes, manifiestan que tener esa guía como documento de consulta en el mismo escenario, sería aún más enriquecedor para hacer un buen trabajo de recolección de indicios con fluidos biológicos, lo cual facilitaría no solo su labor, sino que también les ayuda a pensar por qué se da prioridad a algunos indicios sobre otros, acerca de su manipulación adecuada y la redacción de la solicitud para pedir la pericia adecuada; todo esto a partir del delito cometido y lo que el mismo escenario les vaya «narrando» para aplicar correctamente la Tríada de Selección de Indicios que logra vincular en el mismo escenario a la víctima y al victimario.

Así se genera entonces una descongestión del DCF, el cual podrá emitir dictámenes en un tiempo menor y bajar el pendiente o rezago de informes periciales por emitir.

Este proyecto pretende elaborar una guía para la persona encargada de la recolección de los indicios usados como prueba científica en la investigación judicial. Dicha guía 
considerará su valor probatorio para la resolución del caso, con la aplicación interrelacionada de las normas internacionales de calidad, en concordancia con lo establecido en el Manual de Servicios del DCF, para así recolectar indicios con alto valor pericial forense y optimizar el tiempo de trabajo en el laboratorio al disminuir el ingreso de aquellos indicios con poco valor agregado que podrían sobrecargar los servicios ofrecidos por el laboratorio.

\section{Desarrollo}

Recientemente, el DCF, uno de los tres departamentos que conforman el OIJ, logró acreditar bajo normas de calidad, cierta cantidad de pericias ofrecidas por tres del total de ocho secciones que lo conforman: Pruebas de ADN (Sección de Bioquímica), Alcoholemias (Sección de Toxicología) y Análisis de Drogas (Sección de Química Analítica), en proceso la Unidad de Balística de la Sección de Pericias Físicas.

Conforme la cultura hacia la calidad se iba esgrimiendo entre el personal forense, se empiezan a tomar medidas acerca del tipo de indicios recibidos y sobre su procesamiento, como por ejemplo los que no tienen mayor relevancia para resolver un caso, o bien, los no identificados, es decir, sin su respectiva rotulación; también los que son enviados a la sección equivocada, así como el inadecuado transporte de muchos de ellos, sin tomar en consideración las condiciones de temperatura en la que deben ser transportados. Todo esto se ha hecho del conocimiento al personal de investigación, mediante circulares, memorandos, correos masivos y cápsulas informativas; pero su aceptación no ha tenido la incidencia que se hubiera esperado, debido a que se siguen encontrando inconsistencias al momento de hacer sus aperturas, así como una falencia en la redacción de lo que se desea que Ciencias Forenses le haga a los paquetes remitidos.

Los diferentes indicios hallados en los variados escenarios del delito, en especial los fluidos biológicos, tema que atañe a este trabajo, son recolectados, embalados y transportados al DCF, con su respectiva cadena de custodia y con una solicitud de dictamen pericial emitida por una autoridad judicial (Fiscalía, Juzgado, Tribunal de Juicio), o bien por el Departamento de Medicina Legal (DML) como complemento de alguna valoración o pericia médica.

La especialización forense no es un área a la cual tienen acceso los investigadores, por lo cual es de entender que no se haya logrado fusionar el pensamiento policial con el pensamiento científico; esto, a pesar de existir un Manual de Recolección de Indicios, emitido por el propio DCF, así como capacitaciones varias impartidas tanto a personal de investigación como a fiscales y a defensores.

Una vez efectuada la pregunta de investigación, se presenta la oportunidad de hacer un documento más allá de un Trabajo Final de Graduación (TFG), conforme se inicia con la solicitud de citas con las diferentes jefaturas, el compartir opiniones con las personas involucradas, de forma directa e indirecta, se comienza a visualizar el trabajo tan gigantesco que se está a punto de realizar; entonces se decide delimitarlo y, en vez de hacer una guía para la recolección de indicios general, se convierte en una guía de solo aquellos indicios que provienen de fluidos biológicos, siempre con la posibilidad de dejarla abierta a más, a partir del método propuesto, para que se aplique a cualquier otro tipo de indicio. 
Con la creación de esta guía, se pretende proveer, al personal de investigación, de una herramienta que contenga buenas prácticas del manejo de la escena en relación con los servicios que ofrece el DCF y su valor probatorio, para contribuir con la elaboración de las hipótesis de la dinámica de los hechos, esto con el pensamiento crítico y personal mejor preparado para la atención de los múltiples escenarios del delito; también, se pretende que sea del conocimiento de otras instancias judiciales, tales como el Ministerio Público y la Judicatura.

Así mismo, el tiempo de respuesta hacia el usuario disminuiría considerablemente al entregar dictámenes con mayor valor para la investigación, por lo que la etapa de preparación de juicio sería más corta; es decir, las etapas preparatoria e intermedia, las cuales son base para la acusación, por ende, el beneficio social de este proyecto sería un valioso aporte dentro del proceso penal costarricense.

En este punto, llega el momento de visitar la sección encargada de la recolección de los indicios, en el Valle Central, la Sección de Inspecciones Oculares y Recolección de Indicios (SIORI); allí, el proyecto fue visto con muy buenos ojos y mucho interés, por lo que inmediatamente se facilitó material para empezar con el trabajo.

Aunado a eso, se crea una cultura de rigor científico-criminalístico en el personal de investigación, basado en normas de calidad ISO, asunto que actualmente no se presenta en la práctica real; de esta manera, la labor investigativa del país evolucionaría y se acortaría la brecha en la lucha contra la delincuencia, al tener mejor criterio y buenas prácticas de investigación y recolección de indicios.

Entonces, con la creación de esta guía, se está ante la oportunidad de romper con el paradigma acerca de las Ciencias Forenses como un campo con resultados inminentemente irrefutables con cualquier indicio recolectado y generar la idea de que solo con material de calidad se puede obtener un dictamen pericial objetivo y, por ende, emitir un informe policial con fundamento sólido para ser sometido al siguiente paso: el juicio.

Cuando se inició con las primeras propuestas para realizar este proyecto, a las personas consultadas (jefatura del DCF, jefatura del SIORI, jefatura a.i de la OPO) les pareció muy pertinente, dada la situación de la acreditación y las nuevas directrices emanadas, como por ejemplo, el hecho de emitir un informe criminalístico en el cual se indique lo que se hizo con un indicio de un caso, por ejemplo, de robo, sin sospechoso y con la solicitud que se remitan los posibles sospechosos con la referencia de ese caso y dejar los dictámenes periciales a casos que tuvieran ya un sospechoso con perfil genético para su comparación.

Toda esta iniciativa de ejecutar el proyecto nace tanto de la falta de criterios de selección de indicios y reducción de tiempo y costos, como de la necesidad de eliminar las frases que dicen los mismos investigadores: «Nosotros recolectamos como nos indican en la oficina, en el Curso Básico nos dicen que hagamos algo que luego en la práctica nos dicen que no lo hagamos, es más fácil como se hace en la Delegación, menos complicado, Ciencias Forenses todo lo complica».

La entrada de indicios al DCF, en especial los que están relacionados con fluidos biológicos, ha tendido al alza desde los últimos cinco años, bien puede ser el aumento de 
la criminalidad, la especialización de la delincuencia mediante la organización del crimen, o bien, debido a la cantidad de indicios que se recolectan sin tener un análisis previo de la importancia de dicho indicio como elemento de resolución de un caso.

Se observó, al menos dentro la Sección de Bioquímica, que muchos de los indicios daban resultados negativos, mientras en otros no se tenía idea de algún sospechoso, por lo que se decidió que en ciertos delitos como robos y hurtos, entre otros, se emitiría un informe criminalístico en el cual indicaría que dicho indicio recibido, luego de asignársele un número interno de referencia, se analizaría cuando se tuviera algún sospechoso con el cual comparar, esto comenzó a disminuir el tiempo de respuesta de los casos entrados y el pendiente que manejaba dicha sección empezó a presentar una tendencia a la baja.

Por otra parte, se seguía observando que, en hechos muy sangrientos, como por ejemplo el caso de Matapalo, Guanacaste, en 2016, se recibían demasiados indicios del mismo tipo, por ejemplo, dentro de un mismo embalaje, venían 32 tubos con indicios para determinar sangre y sus respectivas muestras de control, todo de un escenario en donde hubo cinco cuerpos, todos con lesiones producidas con arma blanca; se pedía determinar si la sangre era humana y a quién pertenecía; es decir, se recolectaba la sangre de la pared, del piso, de debajo del cuerpo, de todos los lugares donde hubiera sangre. ¿Con qué fin? ¿Solo para saber si la sangre era de las personas fallecidas? ¿Para vincular al sospechoso con las víctimas y la escena?

Si se desea vincular al sospechoso con una víctima en una escena, pues deben de hallarse indicios dejados por el sospechoso en estas, por ejemplo fluidos biológicos de él en alguna de las víctimas, como semen, ya que se presume que los hechos iniciaron por el reclamo de la violación de una menor, hija de la ofendida fallecida. Se vincula al sospechoso en la escena si se encuentra alguna pertenencia suya, como una gorra, una camiseta, una herramienta con sus huellas dactilares.

¿Cómo se vincula la víctima con el sospechoso? Igual, con algún fluido biológico suyo en ella o de ella en él, por ejemplo residuos subungueales de la víctima con células epiteliales del sospechoso, o bien, sangre de la víctima en las prendas o en la piel de la persona sospechosa.

Para la consecución de esta guía, se hizo un análisis de las estadísticas generadas en la Oficina de Planes y Operaciones (OPO) sobre los delitos más comunes; así como las generadas por la Dirección de Investigaciones Criminales sobre la resolución de casos y cuál fue la pericia que más ayudó en esa resolución; además de las estadísticas del DCF sobre los reportes de inconsistencias debidas a indicios mal recolectados y sin ningún objeto de análisis, también del tiempo de análisis en un dictamen con indicios con valor probatorio.

Solo se tomó en cuenta aquellos indicios relacionados con fluidos biológicos, ya que abarcar a todas las ocho secciones, por su complejidad de especialización, sería objeto de otro estudio de investigación; por su parte, y aunque no esté acreditada aún, se tomó en cuenta el trabajo que hace la Unidad Centralizada de Inspección de Indicios, ya que es un trabajo preliminar en los casos que contienen fluidos biológicos. 
Para recopilar estas estadísticas, se estableció una estrategia para extraer los datos del Sistema Automatizado del (DCF); primeramente, se hicieron reuniones para exponer la problemática y el tema a cada una de las jefaturas correspondientes, así se hizo ver el beneficio de la implementación de este proyecto para la institución, no solo en imagen, por la reducción del tiempo, sino también en la reducción de costos que un buen manejo de la escena trae, tanto en uso de recursos, como de personal; aunque, si bien es cierto la profesionalización requiere cierta inversión, esta se debe analizar desde la perspectiva de costo-beneficio, donde es preferible invertir en capacitación que genere personal que a su vez genere calidad de investigación y no tener que gastar recursos en repeticiones innecesarias de análisis e incluso en pago de horas extra para lograr entregar dictámenes a tiempo.

Como segundo, paso para ir aterrizando la operacionalización del proyecto, se planificó mediante la metodología del Marco Lógico, el cual consiste en expresar, mediante un solo cuadro, la información más relevante o importante de un proyecto, o bien, como lo indica la Comisión Económica para América Latina y el Caribe (CEPAL) en su $\mathrm{Ma}$ nual Formulación de Programas con la Metodología del Marco Lógico, «lo que define a la Metodología del Marco Lógico no es el producto final, sino el proceso que debe seguirse para llegar a la matriz de Marco Lógico» ${ }^{1}$.

Seguidamente, para definir en parte el Marco Lógico, se realizó un análisis de los problemas, sus causas y consecuencias y, así mismo, se buscó las soluciones para esos problemas. A continuación se despliega el árbol de problemas y su árbol de soluciones.

Así, con base en este proyecto, se tiene como principal problema detectado, la carencia de un documento que guíe al personal de investigación (y otros actores) a tener mejor criterio de selección de indicios para que estos tengan valor probatorio; por cual, debido al faltante de este documento, se crea cierto desfase en relación con lo que se aprende en capacitación y lo que se hace en la rutina diaria; esto, en parte es debido al proceso de inducción y capacitación que no se ejecuta desde el primer día, además de que también se nombra a la persona en su puesto y comienza a trabajar, aprendiendo de lo que ve de sus compañeros para, posteriormente, transcurrido cierto tiempo, se le brinde el Programa Básico, por lo que la persona adquiere ciertos vicios procesales; si esta guía se usara, no solo como material didáctico del Programa Básico, sino que además sea de uso en escenario y de consulta en las oficinas o delegaciones, pues se estaría ante una posible solución al problema.

Por otro lado, recolectar por el simple hecho de recolectar, genera que no se sepa qué pericia solicitar o cómo ligar ese indicio con la pericia; por lo que al solicitarla, si no se hace una redacción adecuada, se genera una especie de pausa en el análisis hasta comprender qué se pretende hacer con el indicio remitido; es en esa pausa que muchas veces se determina que ese indicio es innecesario o se comunica que ya el caso se resolvió y que el análisis también es innecesario.

1. Eduardo Aldunate y Julio Córdoba. Formulación de Programas con la Metodología de Marco Lógico. Santiago, Chile: CEPAL-ILPES, 2011. 
Toda esta pausa genera gasto de tiempo pericial, que se pudo haber usado en realizar otra pericia más relevante; pero no solo eso, se genera también una elevación del tiempo de respuesta de la emisión del dictamen con la evacuación de la duda, esto crea lo que se denomina una elevación del pendiente en la producción pericial y genera que, para emitir los dictámenes en el tiempo acordado, se deba laborar tiempo extra, lo cual desgasta al personal y eleva los costos de análisis de la institución.

Conscientes de este pendiente, muchos peritos en su afán de disminuirlo, no hacen la pausa requerida y siguen analizando mientras esperan la respuesta de la consulta; lo cual, como se dijo, a veces la prueba ya no se requiere, por lo que se gastó no solo tiempo, sino también reactivos que pudieron ser usados en otros indicios relevantes. Con esto se puede evidenciar como la falta de criterio de recolección tiene múltiples efectos, incluyendo la elevación del presupuesto.

Así mismo, esta falta de criterio incide con la Dirección Funcional, ya que hay fiscales que solicitan que se recolecte todo porque para ellos todo tiene valor judicial, aunque no necesariamente pericial; a partir de esto se van descartando poco a poco el innecesario, por lo que a veces los investigadores saben que no es tan necesario recolectarlo; pese a que el fiscal lo considere así desde su arista procesal penal. Con esto se genera, aparte de la discrepancia de criterio, una necesidad de capacitación o de refrescamiento forense a los miembros del Ministerio Público, para que estas discusiones sean más consensuadas y que se valore que el OIJ es un ente auxiliar en la investigación y búsqueda de la verdad de una forma fundamentada científicamente y no de manera arbitraria.

Una vez creada la guía, se somete a la revisión de las jefaturas involucradas en el proceso y en el proyecto, quienes ven con buenos ojos el producto final, tanto así que el DCF la utilizará como insumo para hacer la segunda edición del Manual de Recolección de Indicios; así mismo, dentro de la reestructuración que se le hará al Programa Básico de Investigación Criminal (PBIC), se incluyó dicho documento como material didáctico en la materia de Bioquímica.

La guía no solo incluye un capítulo acerca de cómo recolectar los indicios según su valor probatorio, sino que también se tomó en cuenta las condiciones de bioseguridad que deben tener todas las personas que estén en el escenario del delito, como el uso de trajes de bioseguridad mientras se está en el escenario, así como otras medidas de higiene luego de salir; es así porque la idea del uso de trajes especiales cumple dos funciones, la primera es proteger al indicio para que no sea contaminado con ADN de los intervinientes en el escenario del delito y, segundo, para proteger al personal que ingresa de posible enfermedades; ya que, por ejemplo, puede haber un cuerpo con heridas de arma de fuego, con lo cual se le dará importancia a buscar elementos balísticos, orificios de entrada y salida, el arma, el levantamiento del cuerpo, entre otras; pero nunca se sabe si la persona fallecida tenía alguna enfermedad infectocontagiosa de fondo que pudiera provocar algún contagio, sea por la sangre o por algún otro fluido biológico.

Incluye además un capítulo en el cual se explica qué es el TRIAGE y en análisis SOAP para realizar los indicios y escoger así los más prioritarios de análisis según su valor probatorio; el capítulo 3 por su parte, divide cada uno de los fluidos biológicos que tienen valor forense para ser analizados como parte de una investigación judicial; entre 
ellos, semen, saliva, sangre, vísceras, músculos, tejidos, líquidos corporales y cómo debe ser examinado el ADN como evidencia, así como ciertas consideraciones que los fluidos biológicos presentan según las condiciones ambientales en que fueron depositados. Por último, se trata un capítulo sobre las generalidades de la individualización de los indicios y la redacción para completar una solicitud de dictamen pericial, esto con el fin de mejorar la capacidad de expresar, por escrito, qué se desea hacer con el indicio remitido.

También hay un apartado con el glosario respectivo e imágenes ilustrativas y, por supuesto, al principio del documento se explican sus objetivos y el alcance del personal al cual va dirigido.

Finalmente, debido al éxito de la guía, uno de los supervisores que la revisó, hizo la recomendación a la autora para que lo inscriba en el concurso de buenas prácticas; el cual, en el 2019 tuvo su sétima edición, este concurso busca crear buenas prácticas que sean replicables en todas las dependencias judiciales, y se toma en cuenta la innovación, la reducción de costos y, por supuesto, la reproducibilidad.

Siguiendo esta recomendación, se inscribió este proyecto a dicho concurso, del cual resultó ganador del primer lugar en el Ámbito Auxiliar de Justicia; se debe recordar que solo se premian los dos primeros lugares de los tres ámbitos judiciales: Administrativo, Jurisdiccional y Auxiliar de Justicia.

En este proceso, el jurado está conformado tanto por personal judicial como también por representantes del Colegio de Abogados y Abogadas, de la Defensoría de los Habitantes y un decano o representante de alguna universidad que imparta la carrera de Derecho (en esta ocasión le correspondió a la Universidad Latina).

\section{Conclusiones}

Si bien es cierto se obtuvo un premio monetario por la relevancia del proyecto, este fue dado a la oficina que lo presentó y no se recibió a nivel personal, queda la satisfacción de haber entregado un documento, producto de un TFG, que llena a la autora de mucho orgullo y satisfacción; ya que se contribuye no solo al acervo académico con una tesis más, sino que esta a su vez ayuda a mejorar un proceso laboral con reducción de costos, los cuales se verán reflejados una vez que la implementación del uso de la guía perdure en el tiempo. Además se inculca en el personal de investigación el pensamiento crítico al tener un instrumento que indica cómo pensar sus hipótesis cada vez que inicie la investigación de algún caso.

El proyecto de implementación de esta guía está en su fase inicial en este momento; se esperaba que en marzo del 2020 se iniciara con el primer grupo de PBIC, el cual usaría por primera vez la guía, pero la situación de emergencia nacional, provocada por la pandemia del virus SARS-CoV2, el cual causa la enfermedad Covid-19, hizo que se suspendiera, hasta nuevo aviso, el inicio del Programa Básico durante el 2020. Por esto, habrá que esperar las resoluciones y lineamientos que emita el ente rector de salud en Costa Rica para la apertura de cursos presenciales y los protocolos que haya que aplicar. También, esta guía se usará como referencia para el Manual de Recolección de Indicios como un documento en revisión para su segunda edición. 
Se está a la espera de determinar junto con cuál institución, si la universitaria o la judicial, se hará la inscripción de la guía en el ISBN, ya que su contenido es de uso exclusivo a nivel judicial.

Por otro lado, el país tiene poca literatura endémica en criminalística, la gran mayoría de libros y artículos son de origen español, colombiano o argentino, por lo que esta guía contribuye a la literatura costarricense en esa materia.

Se espera que en un futuro cercano, con más graduados de la licenciatura en Criminalística de la Universidad Estatal a Distancia (UNED), se logre profesionalizar la práctica de esta noble carrera en el país; por el momento, la primera generación de criminalistas de la UNED, está dando sus frutos y sus primeros pasos.

\section{ABSTRACT}

Good practice guide for collecting evidence in the crime scene, according to the quality standards of forensic laboratories

This paper presents the methodology followed in a graduate work (TFG) in the area of criminalistics on the problem of lacking a guide with probative value for the evidence collected in a crime scene. A systematic development is generated through the use of the logical framework of the problem. Causes and effects of a possible solution are considered based on the creation of the Guide of good practices to collect evidence in the crime scene, according to the quality standards of forensic laboratories, specifically the indications related to biological fluids.

Key words: Crimininalistics, evidence, biological fluids, DNA.

RÉSUMÉ

Guide de bonnes pratiques dans la collecte d'indices sur une scène de crime, d'après les normes de qualité des laboratoires de police scientifique

Cet article présente la méthodologie suivie dans le Travail de Fin d'Études (TFÉ) du domaine de la criminalistique, et l'analyse du problème de l'inexistence d'un guide avec le sens de valeur probante des indices qui doivent se collecter sur une scène de crime. Dans ce travail, il est généré un développement systématique à travers l'utilisation de l'Approche du Cadre Logique (ALC). Cette approche a permis de trouver les causes et les effets ainsi qu'une solution possible à partir de la conception d'un Guide de bonnes pratiques dans la collecte des indices sur une scène de crime, selon les normes de qualité des laboratoires de police scientifique, notamment les indices matériels rapportés aux fluides biologiques.

Mots-clés: Criminalistique, indices, fluides biologiques, ADN.

\section{Referencia bibliográfica}

Aldunate, Eduardo y Julio Córdoba. Formulación de Programas con la Metodología de Marco Lógico. Santiago, Chile: CEPAL-ILPES, 2011. 